RELAPSE

Post-treatment recurrence of bacteriuria due to the same organism as that originally isolated. Relapse of infection usually occurs within six weeks of cessation of treatment.

\section{PERSISTENT INFECTION}

Bacteriuria persisting during and after treatment.

\section{REINFECTION}

Recurrence of bacteriuria after treatment due to an organism different from that originally isolated. Reinfection with the same organism cannot be distinguished from relapse.

\section{CRITERIA FOR CURE}

In all treatment trials these should be carefully defined. Urine specimens should be collected at specified times after completion of treatment over a defined period (not usually less than six weeks). If the follow-up specimens show no evidence of infection or if reinfection is found the subject is considered to have been cured of the original infection. If the post-treatment specimens show a relapse or the bacteriuria persists treatment may be deemed to have failed.

(Accepted 24 August 1979)

\title{
Committee on the Review of Medicines
}

\section{Recommendations on barbiturate preparations}

British Medical fournal, 1979, 2, 719-720

In 1975 the Committee on the Review of Medicines began a review for the Medicines Commission of the drugs that were already on the market in 1971 when the current procedures for licensing drugs came into effect. Two sets of recommendations have been published in the British Medical fournal, in 1977 $(1977,2,758)$ and $1978(1978,1,1466)$; recommendations on barbiturate preparations are printed below.

\section{Review of barbiturate preparations}

(1) The Committee on the Review of Medicines (CRM) has considered the safety and efficacy of barbiturate preparationswith the exception of phenobarbitone-when used as hypnotics, sedatives, and anti-anxiety agents. Data-sheet guidelines (see below) have been approved which are applicable to the oral use of the following barbiturates and their salts: amylobarbitone, pentobarbitone, butobarbitone, cyclobarbitone, and heptabarbitone. Phenobarbitone, and the use of oral and parenterally administered barbiturates in anaesthesia (including premedication) and epilepsy will be considered later.

(2) The Committee's recommendations were, in general, determined by the known safety hazards of this group of compounds-namely, the high dependency and addiction potential even in "normal" clinical use; the hazards of confusion, falls, and accidental overdosage in the elderly; the high mortality after deliberate or unintentional overdose; and the potential misuse of these drugs. In addition, they considered that safer, efficacious alternative preparations were available in the benzodiazepine group of compounds.

(3) The Committee gave particular consideration to three aspects of barbiturate use-namely, acceptable indications, addiction potential, and patients or individuals in whom it was considered barbiturates should be contraindicated.

(a) Indications for use. The only indication to be recommended by the CRM was for use in intractable insomnia. They considered that on grounds of safety barbiturates should not be indicated routinely for use as hypnotics or prescribed for use as daytime sedatives or anti-anxiety agents. Furthermore, the Committee considered that there was insufficient evidence to establish an anxiolytic action of barbiturates as distinct from the sedative effects. They also considered that indications such as "tension, tension headache, migraine, hypertension, premature ejaculation, neurasthenia, hysteria, psychosis, and amnesia during childbirth" were inappropriate on grounds of safety or safety and efficacy.

(b) Contradications. Under normal circumstances the barbiturates named should not be used in the treatment of the following patients: children and young adults; the elderly and debilitated; women who are pregnant or breastfeeding; and patients with a history of alcohol or drug abuse.

(c) Warning on addiction potential. In view of the known high addiction potential of barbiturates a warning as worded in the data-sheet guidelines should be included under the "further information" section. Particular attention was drawn to the occurrence of dependence and addiction symptoms in the elderly even when the drugs are used in recommended dosage under medical supervision, and the potentially fatal withdrawal symptoms which occur on abrupt cessation of the drugs in all ages.

(4) The CRM also reviewed the 134 barbiturate combination products currently marketed in the UK. On grounds of safety the Committee had reason to think that they might have to advise the licensing authority to revoke the licences for such preparations. Licence holders have been so informed in accordance with the statutory requirements of the Medicines Act, and they have the opportunity of making oral or written representation or both to the CRM before the licensing authority can be advised to revoke the licenses.

(5) Particular concern was expressed about those preparations containing two different barbiturate ingredients because of the increased dependency and addiction potential and the particularly high risk of abuse of such preparations. Of the products in this category, Tuinal was specially mentioned.

(6) In the case of combination products combining barbiturates and non-barbiturate components the reasons given by CRM for taking this view included the following.

(i) Dependency and high addiction potential.

(ii) High mortality after overdosage of barbiturates.

(iii) The dosage may be determined by the non-barbiturate 
component, and this could result in overdosage of the barbiturate ingredient.

(iv) Enzyme induction by the barbiturate ingredient could affect the metabolism of either the non-barbiturate component or any other drug being taken concurrently.

(v) Products containing an analgesic and a barbiturate in combination are not suitable for the treatment of either pain or rheumatic disease.

(vi) With products for the treatment of hypertension there is insufficient evidence that the barbiturate ingredient is effective in such treatment or augments the hypotensive action of the non-barbiturate component.

(vii) With products for the treatment of respiratory and cardiac disorders, the barbiturate ingredient may depress respiration in patients with asthma or bronchitis in whom respiration is already impaired and in patients with chronic respiratory disease.

(viii) (In other cases) there is insufficient evidence that the barbiturate ingredient contributes to the action of the nonbarbiturate component.

(7) The guidelines are concerned with the marketing of these drugs in the UK for medical use of oral barbiturates in clinical practice. They are complementary to the measures being taken at the present time by the Home Office, under Schedule 2 to the Misuse of Drugs Act 1971, which is intended to prevent the misuse of this group of drugs.

\section{Data-sheet guidelines for use of oral barbiturate preparations (excluding phenobarbitone)}

Indications. Severe intractable insomnia.

Contraindications. Uncontrolled pain; children and young adults; the elderly and the debilitated; pregnancy and breast- feeding; patients with a history of alcohol or drug abuse; porphyria.

Drug interactions. Barbiturates cause induction of liver enzymes, so that the availability and blood concentrations of drugs given concurrently that are metabolised in the liver may be affected. These include the following: coumarin-type anticoagulants; systemic steroids (including oral contraceptives); phenytoin; griseofulvin; rifampicin; phenothiazines such as chlorpromazine; tricyclic antidepressants.

Precautions. Reduce dose in patients with renal or hepatic failure.

Warnings and adverse effects. Common adverse effects include drowsiness, sedation, unsteadiness, vertigo, and incoordination. Performance and alertness may be impaired during the first week of administration. Patients should be warned of the possible hazard when driving or operating machinery. These effects may be potentiated by alcohol. Other adverse reactions may include a "hangover" effect, paradoxical excitement, confusion, memory defects, and rashes in patients who may be sensitive to this type of drug.

\section{FURTHER INFORMATION}

Addiction potential. Barbiturates have a high addiction potential. Long-term use or use of high dosage for short periods may lead to tolerance and subsequently to physical and psychological dependence. Symptoms of dependence include confusion, defective judgment, and loss of emotional control. Withdrawal symptoms occur after long-term normal use (and particularly after abuse) on rapid cessation of barbiturate treatment. Symptoms include nightmares, irritability, and insomnia and, in severe cases, tremors, delirium, convulsions, and death. Withdrawal symptoms have been reported in neonates after barbiturate treatment during pregnancy and labour.

\title{
Introduction to Marital Pathology
}

\section{Second phase of marriage}

\author{
J DOMINIAN
}

British Medical fournal, 1979, 2, 720-722

The second stage of marriage is longer than the first and spans some 20 years. During these years the children grow up, the spouses change in their personality, and marital satisfaction drops. A careful analysis of marital satisfaction showed a steady decline from when couples were without children to when they had teenagers, and then an increase to almost the satisfaction of the beginning. ${ }^{1}$ An English study confirmed the decline of marital satisfaction until there are teenagers in the family and the subsequent rise, but this was not to the initial degree of satisfaction. ${ }^{2}$ Since $60 \%$ of divorces occur between the 5 th and 19 th year of marriage, ${ }^{3}$ these years, which roughly constitute the

Central Middlesex Hospital, Acton Lane, London NW10 7NS J DOMINIAN, FRCPE, FRCPSYCH, consultant psychiatrist second phase of marriage, are of great importance. But other work has shown that half of the problems that result in divorce start in the first five years of marriage. ${ }^{4}$

Thus, when we study the problems of the second phase of marriage we find both problems continuous with those of the first five years and new ones. These new problems are not clearly delineated, but frequently include change in one or both partners, which introduces instability into the relationship. Once again the five variables-social, physical, emotional, intellectual, and spiritual-will be described.

\section{Social factors}

During the 20 years from $30-50$ most couples have a stable home; the few exceptions include social class I executives who are required to move at regular intervals. Regular change of accommodation may be stressful because the couple-particularly the wife-are deprived of the support of friends and relatives and have to make new relationships. 